\title{
Feminismo: velhos e novos dilemas uma contribuição de Joan Scott ${ }^{*}$
}

\author{
Érica Melo**
}

\begin{abstract}
Em que corpo cabe o feminismo? Vamos ter que levantar as saias e abrir as calças para demonstrarmos que somos feministas? Todas que autodefinem como mulheres têm o direito de estar nos encontros feministas! O que é ser mulher? ${ }^{1}$
\end{abstract}

Essas questões foram levantadas por duas feministas brasileiras durante o $10^{\circ}$ Encontro Feminista Latino-Americano e do Caribe, em outubro de 2005, por ocasião do debate sobre a inclusão ou não de transexuais em encontros feministas, revelando o peso que a questão identitária ainda tem para o feminismo.

Se a transexualidade é, por um lado, uma nova questão para o feminismo, por outro, é um rearranjo de velhos dilemas em torno do qual o feminismo sempre se deteve: o que é "diferença sexual"? Como e em nome de quem o feminismo se articula? Há estratégias políticas que possibilitem melhores resultados?

$\mathrm{O}$ interessante desse episódio é que o feminismo já tinha sido colocado em xeque anteriormente com relação às categorias de representação e de identidade estável, na medida em que não pôde mais ignorar as especificidades que atravessam a categoria "mulher": raça/etnia, geração, orientação sexual, classe. Dessa

" Resenha de ScotT, Joan. A cidadã paradoxal: as feministas francesas e os direitos do homem. Florianópolis, Ed. Mulheres, 2002 [Trad.: Élvio Antônio Funck]. Recebida para publicação em março de 2008, aceita em julho de 2008.

** Mestre em Sociologia pela Unicamp. ericaisamel@hotmail.com

1 http://www.10feminista.org.br/pt-br/node/170

cadernos pagu (31), julho-dezembro de 2008:553-564. 
Feminismo: velhos e novos dilemas

forma, não podemos mais falar em "mulher" e sim "mulheres". Entretanto, com essa polêmica das transexuais percebemos que, mesmo com a ampliação do termo, o feminismo (ou pelo menos uma parte dele) ainda considera a marca sexual como definidora de gêneros. Mais do que isso, a marca é definidora e inata, uma vez que transexuais mudam de sexo $e$, portanto, se enquadrariam na categoria "mulheres". Aparentemente, a polêmica reside na idéia de que a transexual um dia tenha sido "homem", retomando outra cara questão ao feminismo: a essencialização.

Esse fato ocorrido no Encontro Feminista ressalta a pertinência analítica do estudo sobre o passado $e$, ao mesmo tempo, absolutamente atual o trabalho de Joan Scott sobre o feminismo francês, do século XVIII ao início do XX - A Cidadã Paradoxal - as feministas francesas e os direitos do homem. Nesse estudo, Scott parte de biografias de quatro sufragistas francesas (Olympe de Gouges, Jeanne Deroin, Hubertine Auclert e Madeleine Pelletier) para discutir a história do feminismo, bem como os dilemas do feminismo contemporâneo.

De antemão, Scott rejeita uma perspectiva linear e contínua da história. Para ela, esse tipo de versão impede ver o reverso da experiência feminista e entender suas contradições internas, por exemplo, a repetição de suas lutas que condena a geração seguinte a se confrontar com os mesmos dilemas da geração anterior. Segundo a autora, o que interessa na análise história do feminismo é tentar entender porque tem sido tão difícil estender às mulheres as promessas da Revolução Francesa e a resposta não pode ser resumida à "crônica da luta heróica das feministas", tampouco à uma explicação que dependa de fatores precedentes e externos à política. Para Scott, os conflitos recorrentes do feminismo devem ser vistos como sintomas das contradições nos discursos políticos que produziram o próprio feminismo; em outras palavras, o feminismo nasce a partir das idéias do individualismo, dos direitos e das obrigações sociais do indivíduo e, ao mesmo tempo, critica esse mesmo corpus de idéias ao questionar a 
pretensa universalidade da noção de indivíduo que excluía as mulheres.

Scott afirma que a repetição na história feminista ultrapassa o conflito entre princípios universais e práticas de exclusão e atinge o problema da "diferença sexual". Este, mais que um fato natural, é uma justificativa ontológica para um tratamento diferenciado no campo político e social. E é a partir da questão da "diferença sexual" que se constituiu o paradoxo que permeou toda a história do movimento feminista:

a fim de protestar contra as várias formas de segregação que lhes eram impostas, as mulheres tinham de agir em seu próprio nome, invocando, dessa forma, a mesma diferença [sexual] que procuravam negar (18).

Dessa forma, a história do feminismo é paradoxal, não porque possui estratégias que se opõem entre si, os paradoxos são elementos constitutivos do próprio feminismo, pois é formado por práticas discursivas de política democrática que igualam individualidade e masculinidade, conforme veremos a seguir.

O significado de indivíduo é ambíguo. Pode significar tanto o protótipo abstrato do ser humano (muito usado em teoria política, por filósofos do Iluminismo e por políticos revolucionários da época), como pode significar um ser único, pessoa diferente das outras de sua espécie (conceito de filósofos como Rousseau e Diderot). Entretanto, a busca de uma base comum para a política rejeitou essa segunda noção de diferença. $\mathrm{O}$ indivíduo abstrato é a essência comum da humanidade $e$, assim, abstrai categorias diferenciadoras. Porém, a noção de individualidade, segundo Scott, só pode ser estabelecida por uma relação de contraste: por se referir a um tipo singular, invariável, essa abstração possibilitou a exclusão das/dos que não possuíam as características exigidas para um indivíduo. Nos séculos XVIII e XIX, por exemplo, o desenvolvimento da psicologia da cognição levanta o problema da diferença: órgãos do corpo, tomados como fonte de impressões e 
Feminismo: velhos e novos dilemas

de experiências do indivíduo (cor da pele, órgãos de reprodução), sinalizavam a habilidade humana. Em outras palavras, sinalizavam quem poderia ou não ser incluído na noção de indivíduo e, nesse caso, mulheres e negros estavam fora. Temos, assim, uma contradição: o sistema de inclusão universal exclui o que não se enquadra como um indivíduo, o que não se encaixa em seu protótipo. O protótipo do indivíduo generaliza, e ao mesmo tempo invoca, uma noção única de indivíduo $e$ a unicidade exige uma relação de diferença que a idéia de indivíduo pretendia negar (32). O conceito de indivíduo abstrato não levou em conta questões sobre o processo que estabelecia os limites da individualidade e não permitiu, portanto, a variedade de indivíduos.

A mulher não correspondia ao protótipo humano: era o outro que confirmava a individualidade; a masculinidade era prérequisito para a idéia de indivíduo e atribuir gênero à cidadania foi algo recorrente no discurso político francês, como percebemos em alguns autores retomados por Scott. Para Rousseau, a consciência da diferença sexual e, consequentemente, o desejo de possuir o objeto amado distinguia o homem civilizado do selvagem - esse desejo relacionava tanto o amor que liga um homem a uma mulher, quanto a discórdia política entre os homens. Cem anos mais tarde, Durkheim faz uma analogia entre sua idéia de "solidariedade orgânica" e a heterossexualidade. Para Lombroso, todas as mulheres estão em uma só categoria, mas cada homem é um indivíduo em si, um caso único.

Invocar a "diferença sexual" como explicação dos limites dos direitos individuais possibilitou historicamente o surgimento das feministas, que apontaram as incoerências dos supostos direitos universais (do homem): a noção republicana de indivíduo - sua definição universal e corporificação masculina - era, por elas, posta a nu. Ao questionar, as feministas também assumiam um discurso paradoxal, discutir, ao mesmo tempo, a relevância $e$ irrelevância de seu sexo. A exigência de direitos universais negava a diferença sexual como critério de exclusão, entretanto, ao agir 
em seu próprio nome, as mulheres se utilizavam dessa mesma diferença que outrora não se deveria levar em conta.

A noção de coerência é fundamental para sistemas políticos e ideológicos, como os do republicanismo francês em questão. Ela é indispensável para que haja organização social e os sistemas se posicionem como competentes para praticar e exigir coerência. $\mathrm{Na}$ impossibilidade de sua real existência, tais sistemas políticos negam a contradição interna, a parcialidade ou a incoerência. Nesse sentido, a criação da "diferença sexual" foi uma forma de garantir a exclusão das mulheres.

As feministas aceitaram essa necessidade de coerência $e$ reclamaram que o sistema não cumpria suas próprias exigências. Entretanto, elas também se deram conta que, ao adotar esse mesmo sistema político-ideológico, elas também teriam suas próprias incoerências. Foi então que começaram a questioná-lo e admitir a necessidade de repensá-lo, segundo Scott, "Essa foi (e é) a força e o perigo do feminismo, a razão por que se provocava não apenas medo como também desprezo" (39). As feministas desenvolveram a habilidade de identificar e explorar as ambigüidades nos conceitos fundamentais da filosofia, da política e do senso comum.

Ainda que a noção de um padrão repetido de paradoxos pareça ser intemporal, os conceitos utilizados pelas feministas são frutos de uma época. As reivindicações por direitos por elas formuladas tiveram como base epistemologias diferentes e não devem ser lidas como uma consciência transcendente e contínua da Mulher, tampouco como uma experiência comum de todas as mulheres.

As feministas negavam a idéia de "diferença sexual" como resposta à exclusão da participação política das mulheres. Entretanto, ao agir em nome das mulheres, invocavam a mesma diferença que pretendiam negar (sendo a idéia de "diferença sexual" parte desses mesmos discursos), um paradoxo que desafia a tradição, acentua suas contradições, sem, contudo, abalar as crenças ortodoxas. 
Feminismo: velhos e novos dilemas

Essa contradição é atualmente perceptível nos debates sobre "igualdade" ou "diferença" no feminismo: as mulheres são iguais aos homens e por isso devem reivindicar os mesmos direitos ou são diferentes e, por causa ou apesar das diferenças, exigem os mesmo direitos? Essa dicotomia, segundo Scott, invisibiliza que ambas as posições atribuem identidades fixas $e$ análogas a homens e mulheres e, implicitamente, endossam a existência de uma definição de diferença sexual. A conseqüência desse raciocínio é que, mais uma vez, a diferença sexual é percebida como um fenômeno da natureza (reconhecível, mas mutável) quando, no entanto, é mais um fenômeno indeterminado, como etnia, cujo significado está sempre em discussão.

Ainda que o período estudado por Scott pareça distante, 1789 a 1944, é inegável a contemporaneidade da luta política dessas primeiras feministas, por exemplo, a luta pela paridade na representação política das mulheres, mesmo que as feministas tenham opiniões distintas sobre a questão. A polêmica sobre a entrada ou não das transexuais no feminismo é outro exemplo $e$ mais uma vez, a natureza - a "diferença sexual" - é invocada para fundamentar o debate.

A política feminista é marcada por essa indefinição do que vem a ser "diferença sexual". Entretanto, para Scott, essa ambigüidade não se caracteriza como um problema para o feminismo. Ao contrário, é o que lhe dá intensidade:

se por um lado, pareciam aceitar definições de gênero como verdadeiras; por outro, elas as recusavam. Aceitação $e$ recusa simultâneas punham a nu as contradições $e$ omissões nas definições de gênero que eram aceitas em nome da natureza e impostas por lei. As reivindicações feministas revelaram os limites do princípio de liberdade, igualdade e fraternidade e levantaram dúvidas em relação a sua aplicabilidade universal (19).

Através da teoria pós-estruturalista, Scott encontra uma forma mais apropriada para criticar a história do feminismo e ao 
feminismo em si, que permitiu analisar as construções de significado $e$ as relações de poder, uma vez que essa teoria questiona categorias unitárias $e$ universais que naturalizam conceitos históricos, como "homem" e "mulher".

O pós-estruturalismo e o feminismo contemporâneo são movimentos de fins do século XX que compartilham uma certa relação crítica auto-consciente diante das tradições política e filosófica estabelecidas (Scott, 2000:204).

O conceito de diferença, seguindo a linha da lingüística estruturalista de Saussure, baseado na noção de que o significado é construído através do contraste (que pode ser implícito ou explícito), trabalha com a idéia de que uma definição positiva se apóia em sua negação ou repressão de algo que se representa como antitético a ela, é o que baliza toda a discussão do feminismo como paradoxal. Para Scott, essas oposições fixas ocultam que os termos apresentados como opostos são, na verdade, interdependentes e hierárquicos: o significado de um termo depende de um contraste estabelecido, não de algo inerente ou de uma simples antítese. Essa idéia permeia toda a análise de Scott sobre as sufragistas francesas.

Além da contemporaneidade das reivindicações dessas feministas históricas, uma outra possibilidade que a análise histórica oferece é a de rever como a história do feminismo tem sido percebida e construída, afetando as práticas atuais. Scott rejeita a abordagem teleológica ${ }^{2}$ por ser uma versão que apenas

2 Scott utiliza o termo para se referir à forma, herdada das feministas do século XIX, como a história do feminismo é apresentada: "Elas [as feministas do séc. XIX] construíram uma história que não poderia ter se afastado das grandes metas de evolução do seu tempo; uma história teleológica, que progride cumulativamente em direção a um objetivo ainda não atingido; uma história na qual as mulheres, inevitavelmente, encontraram dentro de si próprias os meios para lutar contra sua exclusão das políticas democráticas; uma história na qual as feministas tranformaram, por força de sua imaginação, as ações caóticas e 
Feminismo: velhos e novos dilemas

permite saber que as feministas usaram uma ou outra estratégia (no caso, a estratégia da "diferença" ou da "igualdade"), mas não como foram construídas - saber de sua existência permite uma crítica das práticas normativas, mas não a extensão dessa crítica. A experiência não é evidente, e tratá-la como tal impede a análise de sua historicidade, pois a reproduz em seus termos (Scott, 1999:5).

As narrativas biográficas das feministas francesas, feita por Scott, também não guardam uma relação de causa e efeito, entre experiência pessoal e atividade individual. $\mathrm{O}$ enfoque biográfico parece reafirmar a noção de que a ação é uma expressão autônoma, mas, na verdade, é o efeito de um processo historicamente definido. Ainda que a noção do agir seja, com freqüência, apresentado como condição da natureza humana, é um conceito específico, ligado historicamente às mesmas idéias que negavam à mulher individualidade, autonomia e direitos políticos.

Dois principais argumentos são desenvolvidos ao longo do livro. Primeiro, a ação feminina se expressa paradoxalmente, conformada pelos discursos do individualismo universal que elege a "diferença sexual" como justificativa para a exclusão da mulher. Segundo, a história da militância feminista não é um conjunto fixo de comportamentos da mulher, mas uma conseqüência de ambigüidades e contradições dentro de epistemologias específicas. Através dos paradoxos historicamente específicos, Scott se propõe a (re)escrever a história do feminismo.

Em última instância, tratar a história do feminismo como paradoxo também contesta as histórias da democracia que atribuem à exclusão da mulher ao voto a falhas temporárias dos sistemas políticos em contínua expansão e que, na medida em que elas foram incluídas posteriormente, era um indicador de ausência de desigualdade social.

disparatadas das mulheres do passado em uma tradição organizada e contínua" (23). 
Sem entrar na análise da vida de cada uma das feministas que compõe o livro, pontuo suas investidas políticas na "perspectiva paradoxal" proposta por Scott.

A Declaração dos Direitos da Mulher e da Cidadã, escrita por Olympe de Gouges, em 1791, pode ser considerada a primeira manifestação feminista. Ao reivindicar que as mulheres fossem representadas como cidadãs, utilizando-se dos limites da pretensão universal da definição de indivíduo abstrato da Declaração dos Direitos do Homem e do Cidadão, Gouges expôs a primeira contradição da proposta revolucionária de igualdade, fraternidade e liberdade. A saída para os revolucionários de sua época foi a justificativa da "diferença sexual", que, por si só, explicaria a relação mulher/espaço privado e homem/espaço público. A idéia de uma mulher atuando na política provocou nos revolucionários da época uma imagem de ambigüidade, de androginia. Fora de seu domínio "natural", a mulher se torna um ser indefinido.

Olympe de Gouges rompeu com vários papéis atribuídos às mulheres: foi uma escritora que produziu intensamente, recusou o nome paterno e do marido, escreveu peças teatrais feministas e abolicionistas e, acusada de viver excessos da imaginação, foi condenada à morte pela guilhotina em 1793.

Jeane Deroin, militante socialista, se candidata ao parlamento com o intuito de desmascarar a lei, que excluía as mulheres de votar e serem votadas, ainda que sua existência fosse baseada na idéia de "igualdade" dos cidadãos. Assim como Gouges, recusou o sobrenome do marido. Sua luta pela inclusão política das mulheres foi marcada por idéias sobre a maternidade que, para ela, tratava-se de um trabalho social e não de um destino biológico, - a mãe é a idealização máxima da cidadania, pois os filhos são obra da mulher. Deroin foi presa em 1850 e, em 1851, partiu para o exílio na Inglaterra, onde permaneceu militando pelo feminismo e pelo socialismo até sua morte em 1894. 
Feminismo: velhos e novos dilemas

Hubertine Auclert atuou intensamente no debate político do final do século XIX, no qual o significado de cidadania estava definido em relação ao direito ao trabalho como condição ao direito à propriedade. Auclert insistia na necessidade das mulheres trabalharem e no reconhecimento do trabalho doméstico como "sagrado", já que seu valor econômico era essencial para a sociedade. Ela afirmava a existência de interesses particulares das mulheres, justificando seu ingresso no mundo da política. Para ela, interesses masculinos e femininos seriam opostos. Refletir sobre o significado da linguagem e a falta, na língua francesa, de nominações no feminino de determinadas profissões, questão extremamente atual, questionava como as mulheres poderiam exercê-las se elas sequer existiam nos dicionários.

Madeleine Pelletier, outra feminista analisada por Scott, foi atuante no início do século XX. Marcada pela descoberta do inconsciente, para ela, a identidade feminina era uma forma de opressão interiorizada. A diferença sexual seria um conjunto de fenômenos psicológicos, não físicos. Na tentativa de abolir qualquer diferenciação entre masculino e feminino, ela tentava desconstruir a idéia de diferença sexual e eliminar a subordinação imposta às mulheres se comportando de forma "masculinizada", por exemplo, vestir-se com trajes masculinos. Tal atitude, novamente, provocou no imaginário dos intelectuais da época a idéia de androginia, fato que agradava Pelletier por perceber que, de fato, desafiava as normas de exclusão.

A idéia de ambigüidade ou indefinição sexual acompanhou, em maior ou menor grau, as investidas de todas as feministas aqui tratadas. Num outro estudo sobre a natureza imaginária do gênero, a antropóloga Mariza Corrêa (2003) também discute a questão. Para ela,

a trajetória de algumas personagens femininas põe em xeque a suposta impermeabilidade das categorias masculino/feminina no sistema de classificações de gênero. Quando seres socialmente definidos como parte da cena 
privada são encontrados na cena pública, a ambigüidade de sua posição os coloca numa categoria anômala, como integrantes de uma espécie de "natureza imaginária.

A autora analisa o caso de mulheres que, ao ocuparem o espaço público, ou seja, fora do seu "espaço natural", têm seu estatuto definido de forma ambígua, não são nem homens, nem mulheres, mas andróginos. Separando-se sexo de gênero, fica claro que as definições de feminino e masculino são explicitadas em disputas pelo poder, pelo prestígio ou por privilégios.

Ao final, Scott retoma algumas questões, apresentadas no início da obra, sobre o feminismo contemporâneo, relacionando-o às questões políticas das militantes apresentadas ao longo dos três séculos. O debate atual na França em torno das lutas pela paridade na representação política das mulheres demonstra a contemporaneidade das feministas históricas.

Sua intenção em expor a disputa feminista em torno de posições de igualdade ou de diferença foi demonstrar um sintoma da dificuldade que a diferença sexual representa para se chegar a uma concepção de singularidade do indivíduo. O feminismo, construído numa relação paradoxal com esse conceito de indivíduo singular, reproduz, inevitavelmente, os termos contraditórios de sua própria construção. E é próprio da natureza do paradoxo ser insolúvel, portanto, as feministas não resolveram os paradoxos de suas épocas, como também não podem resolvêlos atualmente, nem mesmo torná-los mais fáceis de resolver.

\section{Referências bibliográficas}

CORRÊA, Mariza. Antropólogas e antropologias. Belo Horizonte, Editora da UFMG, 2003.

SCOTT, Joan W. A cidadã paradoxal - as feministas francesas e os direitos do homem. Florianópolis, Ed. Mulheres, 2002 [Trad.: Élvio Antônio Funck]. 
Feminismo: velhos e novos dilemas

Igualdade versus diferença: os usos da teoria pósestruturalista. Debate Feminista (Cidadania e Feminismo), $n^{\circ}$ especial, 2000, pp.207-218.

Experiência. In: SILVA, Alcione da. et alli. Falas de Gênero. Florianópolis, Ed Mulheres, 1999, pp.21-55. 